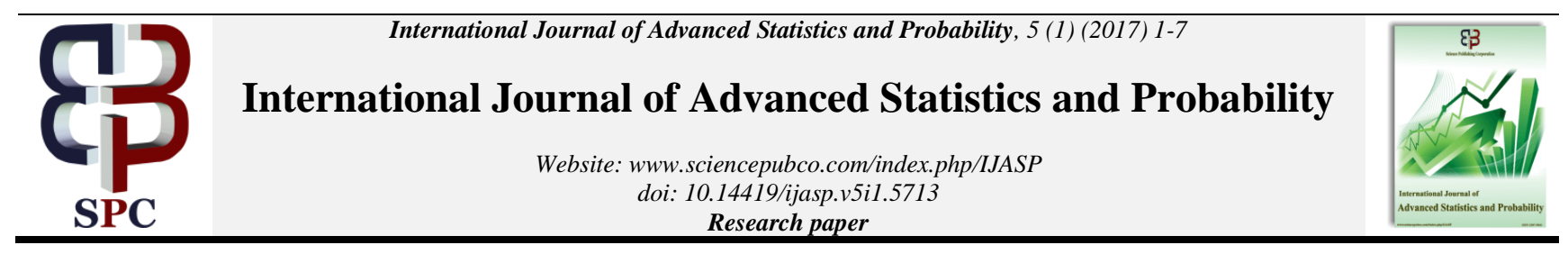

\title{
Multivariate statistical process control approach to monitor quality of chloroquine phosphate tablet (bp250mg) in Dana pharmaceutical company
}

\author{
Umar Abubakar Adamu ${ }^{1 *}$, Gulumbe Shehu Usman' ${ }^{2}$ Dikko Hussaini Garba ${ }^{1}$ \\ ${ }^{l}$ Department of Mathematics, Ahmadu Bello University, Zaria-Nigeria \\ ${ }^{2}$ Department of Mathematics, Usman Danfodio University, Sokoto-Nigeria \\ *Corresponding author E-mail:aaumar4real@yahoo.com
}

\begin{abstract}
Recently, much attention has been raised on effects of high increase in drugs counterfeiting and sub-standard quality which leads to many casualties in Nigeria. The Multivariate Statistical Process Control Charts approach was employed to examine such defects especially in assessing the official physico-chemical quality of chloroquine phosphate tablet (BP250mg) which claimed to contain the required quality properties. The Multivariate Exponentially Weighted Moving Average (MEWMA) Control Chart gives a powerful and reliable control chart than the widely used Hotelling's $\mathrm{T}^{2}$-Control Chart, which detects the smallest shift in the product process means and have minimum process variability. Also, the Matrix of scatter plots indicated the existence of relationship among the process variables and the Principal Component Analysis (PCA) minimized the rate of dimensionality of the process variability, which captured most of the variables outliers and retained the first Principal Components (PC) that explained over $99 \%$ variability of the product. To this end, the study results shows that the product quality characteristics (process variables) is under control (stable) and conform to international standard as specified by BP 2002 .
\end{abstract}

Keywords: Chloroquine Tablet; Hotelling's T2 Control Chart;Mewma Control Chart; MSPC; PCA.

\section{Introduction}

Multivariate Statistical Process Control (MSPC) emerged as a classical tool due to high increase on production processes in industries because several quality characteristics need to be monitored simultaneously. The MSPC cater the defects in monitoring two or more quality characteristics of production processes. Most of the quality engineers and manufacturers make used of MSPC in monitoring complex production processes towards achieving high quality product and services to meet international standard and overlap competitive market [10]. Therefore, Statistical Process Control is a powerful collection of problem-solving tools useful in achieving process stability and improving quality of a product through reduction of variability [16].

[1] [4] [8] and [9] emphasized on the use of Statistical Process Control (SPC) as effective approach for monitoring and diagnosing of production processes toward meeting the international standard and to survive competitive market among industries.

[9] and [7] suggested that MEWMA Control Chart may be an effective and reliable alternative approach for the traditional Hotelling's $\mathrm{T}^{2}$ Control Chart in term of quick detecting of small shift in process means and minimum variability of production processes, because as number of process variable increases, the Hotelling's $\mathrm{T}^{2}$ Control Chart loses efficiency in detecting a small and even moderate shift in the mean vectors.[6] proposed and developed the MEWMA Control Chart concept to cater such problems of detecting minor shift and provide more sensitivity in quick detection of small mean shifts and variability in the product processes. The Multivariate Control Chart Scheme is pretty efficient in issuing a warning signal on a small amount of mean shift at the right time which is more suitable for the pharmaceutical industries and other related services [9].

[18] On the study of side effects of chloroquine, describes Drug Quality Control as part of Good Manufacturing Practice (GMP) which is concerned with Sampling, Specifications and Testing of drugs product towards meeting the international standards. [11] pointed out that Drug Quality Control has constantly observed a rapid and remarkable growth as it embraces the control of Pharmaceutical Products. [12] Assessed physico-chemical properties of chloroquine tablet product produced by some selected major Nigerian and Foreign Pharmaceutical Industries using some Calibration Curve techniques, were the results indicated the importance of stringent quality control of drugs in Nigeria.

[2], [5] and [14] Study the unofficial quality characteristics of different brands of chloroquine tablets available in Nigeria.The results stated that most brands of the tablet failed the physicochemical quality tests. [17] emphasized on ways of optimizing and sustaining quality of tablets circulating in the African region toward meeting international standard through regularly research by regulatory agencies and academicians, were the study indicated that some of the major causes of substandard and counterfeiting tablets circulating in Africa are as a results of lack of proper legal base, poor linkage with regulatory agencies, lack of proper management and absence of information on quality of drugs. 


\section{Materials and methods}

The data used in this study is an experimental laboratory work carried out in the Department of Pharmaceutics and Pharmaceutical Microbiology, Ahmadu Bello University, Zaria. It comprises of forty process measurement of four official Quality Characteristics (Process Variables) of the product namely: Disintegration Time $(\min )=X_{1}$, Dissolution Rate $(\%)=X_{2}$, Mean Weight $(\mathrm{mg})=$ $\mathrm{X}_{3}$ and Active Content $(\%)=\mathrm{X}_{4}$.

Melter electronic balance, spectrum lab 752S UV VIS spectrphometer, erwekadisintergration test apparatus, erweka dissolution test apparatus, thermometer, friabilator, filter paper and distilled water were used to carry out the experimental work. In all, forty chloroquine phosphate tablets were randomly purchased from pharmacy outlets, patient medicine and vendor shops for the study of identification test, disintegration test, and assay for the content of active ingredient of the tablets as specified by [3].

The statistical methods used are the classical Multivariate techniques such as, Multivariate Normal Distribution, Hotelling's $\mathrm{T}^{2}-$ Control Chart, MEWMA Control Chart and PCA approaches towards achieving the study objectives.

\subsection{Multivariate normal distribution}

The multivariate normal density is a generalization of the univariate normal density with Quality Characteristics (Process Variables) $\mathrm{P}$, for $\mathrm{P} \geq 2$ dimensions. In univariate statistical quality control, we generally make use of the normal distribution to describe the behavior of a continuous process variable $\mathrm{P}$ [18]. The univariate normal probability density function is given as:

$f(x)=\frac{1}{\sqrt{2 \pi \sigma^{2}}} e^{-\frac{1}{2}\left(\frac{x-\mu}{\sigma}\right)^{2}},-\infty<x<\infty$

It is more convenient to denote the mean of the normal distribution as $\mu$ and the variance as $\sigma^{2}$ is $N\left(\mu, \sigma^{2}\right)$. Apart from the negative sign, the term in the exponent of the normal distribution in equation (1) can be expressed as follow:

$\left(\frac{x-\mu}{\sigma}\right)^{2}=(x-\mu)\left(\sigma^{2}\right)^{-1}(x-\mu)$

This quantity measure the squared standardized distance (errors between the finished product and target mean) from $\mathrm{x}$ to the mean $\mu$.

Assumed that we have p-variables (product process variables), given by $\mathrm{x}_{1}, \mathrm{x}_{2}, \ldots, \mathrm{x}_{\mathrm{p}}$. We can now arrange these product process variables in a $\mathrm{p}$-component for a $\mathrm{p} \times 1$ vector $\boldsymbol{x}^{\prime}=\left[\mathrm{x}_{1}, \mathrm{x}_{2}, \ldots, \mathrm{x}_{\mathrm{p}}\right]$. Let $\mu^{\prime}=\left[\mu_{1}, \mu_{2}, \ldots, \mu_{\mathrm{p}}\right]$ be $\mathrm{p} \times 1$ Mean Vectors of the process variables ( $\mathrm{x}$ 's) and let the variances and covariance's of the random variable in $\mathrm{X}$ be contained in a $\mathrm{p} \times \mathrm{p}$ covariance matrix $\Sigma$. The main diagonal elements of $\Sigma$ are the variances of the process variables ( $\boldsymbol{x}$ 's) and the upper diagonal elements are the covariance's. Therefore, the squared standardized (generalized) distance from $x$ to $\mu$ can be given as:

$\left(\frac{x-\mu}{\sigma}\right)^{2}=(x-\mu)^{\prime} \Sigma^{-1}(x-\mu)$

The Multivariate Normal Distribution density function is obtained simply by replacing the standardized distance of the product process variables in equation (2) by the Multivariate Generalized
Distance in Equation (3) and changing the constant term $1 / \sqrt{2 \pi \sigma^{2}}$ to a more general form as $(2 \pi)^{\mathrm{p} / 2}|\Sigma|^{1 / 2}$ makes the area under the probability density function unity regardless of the value of the process variables (p). This is necessary, because in the multivariate cases, the probabilities are represented by the volumes under the surface over the region defined by interval of the $(\boldsymbol{x}$ 's) values [13]. Therefore, the multivariate normal probability density function becomes:

$$
\begin{aligned}
& \mathrm{f}(\boldsymbol{x})=\frac{1}{(2 \pi)^{\mathrm{p} / 2}|\Sigma|^{1 / 2}} \mathrm{e}^{-\frac{1}{2}(x-\mu)^{\prime} \Sigma-1(x-\mu)}, \\
& -\infty<x_{\mathrm{j}}<\infty, \mathrm{j}=1,2, \ldots, \mathrm{p}
\end{aligned}
$$

We can now denote this process variables P-dimensional normal density as $\mathrm{N}_{\mathrm{p}}(\mu, \Sigma)$, which is analogous to the normal density in the case of univariate [13].

\subsection{The Hotelling's $\mathbf{T}^{2}$-distribution}

The Hotelling's $T^{2}$ distribution is a multivariate statistical techniques used for testing of hypothesis concerning mean vectors and is applicable in accessing statistical quality control approaches [1][15].

Therefore, Hotelling's $\mathrm{T}^{2}$ distribution is demonstrated using the univariate test of hypothesis. The null hypothesis $\mathrm{H}_{0}: \mu=\mu_{0}$ against the alternative hypothesis $H_{1}: \mu \neq \mu_{0}$. Where $\mu$ is the population mean and $\mu_{0}$ is likely value for the population mean.

Suppose that $\mathrm{x}_{1}, \mathrm{x}_{2}, \ldots, \mathrm{x}_{\mathrm{n}}$ denoted a random sample from a normal population, the appropriate test statistic is given as:

$\mathrm{t}=\frac{\left(\overline{\mathrm{x}}-\mu_{0}\right)}{\mathrm{s} / \sqrt{\mathrm{n}}}$

where:

$\overline{\mathrm{X}}=\frac{1}{\mathrm{n}} \sum_{\mathrm{i}=1}^{\mathrm{n}} \mathrm{x}_{\mathrm{i}}$

$\mathrm{S}^{2}=\frac{1}{\mathrm{n}-1} \sum_{\mathrm{i}=1}^{\mathrm{n}}\left(\mathrm{x}_{\mathrm{i}}-\overline{\mathrm{x}}\right)^{2}$

The test statistics has a student's t-distribution with n-1 degrees of freedom. However, the natural generalization of the squared distance in the multivariate approach becomes:

$\mathrm{T}^{2}=\mathrm{n}\left(\overline{\mathrm{X}}-\mu_{0}\right)^{\prime} \mathrm{S}^{-1}\left(\overline{\mathrm{X}}-\mu_{0}\right)$

where:

$$
\underset{\mathrm{p} \times 1}{\overline{\mathrm{x}}}=\frac{1}{\mathrm{n}} \sum_{\mathrm{i}=1}^{\mathrm{n}} \mathrm{X}_{\mathrm{i}}
$$

$\underset{p \times p}{S}=\frac{1}{n-1} \sum_{i=1}^{n}\left(X_{i}-\bar{X}\right)\left(X_{i}-\bar{X}\right)^{\prime}$ 


$$
\mu_{0} \times 1=\left[\begin{array}{c}
\mu_{10} \\
\mu_{20} \\
\cdot \\
\cdot \\
\mu_{\mathrm{p} 0}
\end{array}\right]
$$

Hence, the test statistic $\mathrm{T}^{2}$ is called the Hotelling's $\mathrm{T}^{2}$ distribution. $\bar{X}$ is the sample mean vector, $S$ is the estimated covari$\mathrm{p} \times 1$ $\mathrm{p} \times \mathrm{p}$

ance matrix of $\overline{\mathrm{X}}$ and $\mu_{0}$ is known as the plausible value of the $\mathrm{p} \times 1$

population mean $\mu$.

\subsection{Hotelling's $T^{2}$-control chart}

The Hotelling $\mathrm{T}^{2}$-Control Chart is built on the general idea of testing the hypothesis that the mean vector $(\mu)$ of a Multivariate Normal Distribution is equal to a constant vector $\left(\mu_{0}\right)$ against the alternative hypothesis that the mean vector $(\mu)$ is not equal to that constant $\left(\mu_{0}\right)$.

Hotelling's $\mathrm{T}^{2}$-Control Chart is described as one of the most familiar Multivariate Process Control procedures for monitoring the mean vectors variability of the product process variables in most of the industries for sustaining effective quality of their products to meet with international standard [13]. This procedure requires computing the sample mean for each of the p process variables from a sample of size $n$. This set of process variable means can be represented as a $\mathrm{p} \times 1$ vector below:

$$
\underset{\mathrm{p} \times 1}{\overline{\mathrm{X}}}=\left[\begin{array}{c}
\overline{\mathrm{X}}_{1} \\
\overline{\mathrm{X}}_{2} \\
\cdot \\
\cdot \\
\overline{\mathrm{X}}_{\mathrm{p}}
\end{array}\right]
$$

The test statistic plotted on the Hotelling's $\mathrm{T}^{2}$ Control Chart for each sample is given as:

$$
\mathrm{T}^{2}=\mathrm{n}(\overline{\mathrm{X}}-\mu)^{\prime} \Sigma^{-1}(\overline{\mathrm{X}}-\mu)
$$

Where $\mu^{\prime}=\left[\mu_{1}, \mu_{2}, \ldots, \mu_{p}\right]$, is the vector of in-control means for each product process variables and $\Sigma$ is the covariance matrix. The $\mathrm{p} \times \mathrm{p}$ sample covariance matrices $(\mathrm{S})$ are formed as follows:

$$
S=\left[\begin{array}{cccccc}
s_{11} & s_{12} & \cdot & \cdot & \cdot & s_{1 p} \\
S_{21} & s_{22} & \cdot & \cdot & \cdot & s_{2 p} \\
\cdot & \cdot & \cdot & & & \cdot \\
\cdot & \cdot & & \cdot & & \cdot \\
\cdot & \cdot & & & \cdot & \cdot \\
S_{p 1} & s_{p 2} & \cdot & \cdot & \cdot & s_{p p}
\end{array}\right]
$$

Therefore, the sample covariance matrices above, is an unbiased estimate of the population covariance matrix $\Sigma$ whenever the product process is in-control.

Thus,

$$
\Sigma=\left[\begin{array}{cccccc}
\sigma_{11} & \sigma_{12} & \cdot & \cdot & \cdot & \sigma_{1 \mathrm{p}} \\
\sigma_{21} & \sigma_{22} & \cdot & \cdot & \cdot & \sigma_{2 \mathrm{p}} \\
\cdot & \cdot & \cdot & & \cdot \\
\cdot & \cdot & & \cdot & & \cdot \\
\cdot & \cdot & & \cdot & \cdot \\
\sigma_{\mathrm{p} 1} & \sigma_{\mathrm{p} 2} & \cdot & \cdot & \cdot & \sigma_{\mathrm{pp}}
\end{array}\right]
$$

Furthermore, suppose the sample covariance matrix $\mathrm{S}$ above in equation (15), is used to estimate the covariance matrix $\Sigma$ and the vector $\overline{\bar{X}}$ is taken as the in-control value of the mean vector of the production processes, then replacing $\mu$ with $\overline{\bar{X}}$ and $\Sigma$ with $S$ in the equation (14), the test statistic becomes:

$$
\mathrm{T}^{2}=\mathrm{n}(\overline{\mathrm{X}}-\overline{\overline{\mathrm{X}}})^{\prime} \mathrm{S}^{-1}(\overline{\mathrm{X}}-\overline{\overline{\mathrm{X}}})
$$

Therefore, this procedure is called the Hotelling's $\mathrm{T}^{2}$-Control Chart and possesses the ability to detect shift in the mean vectors which depends merely on the magnitude of the shift and less concerned on the direction of the production processes [18]. There are two Distinct Phases in the application of Control Charts namely, Phase I and Phase II.

\subsubsection{The phase I}

This is useful in establishing Upper Control Limit (UCL) with the corresponding Lower Control Limit (LCL) and testing whether the production processes is in statistical control or otherwise, when the $m$ preliminary subgroups were drawn and the sample statistic $\overline{\bar{X}}$ and $\mathrm{S}$ are computed. Therefore, once the set of observations in Phase I is in-control, it is certain that the control limits in the next Phase can be established freely. The Phase I is sometimes called a Retrospective Analysis and comprises with the following control limits in the $\mathrm{T}^{2}$ Control Chart as:

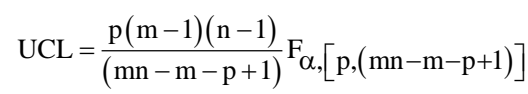

$\mathrm{LCL}=0$

\subsubsection{The phase II}

This stage is useful in monitoring the future production processes and acquired with the following control limits as:

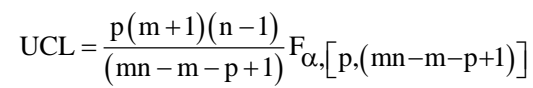

$$
\mathrm{LCL}=0
$$

Furthermore, when $\mu$ and $\Sigma$ are estimated from a large number of preliminary samples, it is usually normal to make use of the approximation to chi-square distribution control limits [18].

\subsection{Multivariate EWMA control chart}

The statistic for MEWMA is defined as:

$$
Z_{i}=\lambda X_{i}+(1-\lambda) Z_{i-1}
$$

Where $\mathrm{Z}_{0}$ is assumed $\mathrm{p}$-dimensional null vector $\mu_{0}=0_{\mathrm{p}}$ and $\lambda$ is a parameter with the range $0<\lambda \leq 1$, which specifies the magnitude of the smoothing. The MEWMA control chart indicates a 
warning signal alarm immediately the process is out-of-control provided the quantity below hold:

$\mathrm{Q}_{\mathrm{i}}=\mathrm{Z}_{\mathrm{i}}^{\prime} \Sigma^{-1} \mathrm{Z}_{\mathrm{i}}>\mathrm{H}$

Where $\mathrm{H}>0$, is a selected value towards achieving a stable process using the Average Runs Length (ARL) table of MEWMA.

\subsection{Derivation of principal component analysis}

The Principal Component Analysis is concerned with explaining the variance-covariance structure of a set of variables through a few linear combinations of these variables. Its general objectives are to reduce process variables $\mathrm{p}$ data and provide effective interpretation of the entire processes. An analysis of principal components often reveals the relationships that were not previously suspected and provides effective interpretations of the results [7].

Suppose the product process variables random vector $\boldsymbol{X}^{\prime}=\left[\mathrm{X}_{1}, \mathrm{X}_{2}, \ldots, \mathrm{X}_{\mathrm{p}}\right]$ have the covariance matrix $\boldsymbol{\Sigma}$ with eigenvalues $\lambda_{1} \geq \lambda_{2} \geq \ldots \geq \lambda_{\mathrm{p}} \geq 0$.

We can now consider the linear combinations of the process variables as:

$$
\begin{aligned}
& \mathrm{Z}_{1}=\boldsymbol{c}_{\boldsymbol{1}}^{\prime} \boldsymbol{X}=\mathrm{c}_{11} \mathrm{X}_{1}+\mathrm{c}_{12} \mathrm{X}_{2}+\ldots+\mathrm{c}_{1 \mathrm{p}} \mathrm{X}_{\mathrm{p}} \\
& \mathrm{Z}_{2}=\boldsymbol{c}_{2}^{\prime} \boldsymbol{X}=\mathrm{c}_{21} \mathrm{X}_{1}+\mathrm{c}_{22} \mathrm{X}_{2}+\ldots+\mathrm{c}_{2 \mathrm{p}} \mathrm{X}_{\mathrm{p}}
\end{aligned}
$$

$\mathrm{Z}_{\mathrm{p}}=\boldsymbol{c}_{\boldsymbol{p}}^{\prime} \boldsymbol{X}=\mathrm{c}_{\mathrm{p} 1} \mathrm{X}_{1}+\mathrm{c}_{\mathrm{p} 2} \mathrm{X}_{2}+\ldots+\mathrm{c}_{\mathrm{pp}} \mathrm{X}_{\mathrm{p}}$

Thus,

$$
\begin{aligned}
& \operatorname{Var}\left(\mathrm{Z}_{\mathrm{i}}\right)=\boldsymbol{c}_{\mathrm{i}}^{\prime} \Sigma \boldsymbol{c}_{\boldsymbol{i}}, \quad \mathrm{i}=1,2, \ldots, \mathrm{p} \\
& \operatorname{Cov}\left(\mathrm{Z}_{\mathrm{i}}, \mathrm{Z}_{\mathrm{j}}\right)=\boldsymbol{c}_{\mathrm{i}}^{\prime} \Sigma \boldsymbol{c}_{\boldsymbol{j}},
\end{aligned}
$$

Therefore, the principal components are those uncorrelated linear combinations $\mathrm{Z}_{1}, \mathrm{Z}_{2}, \ldots, \mathrm{Z}_{\mathrm{p}}$ whose variables are as large as possible. The $\mathrm{Z}_{\mathrm{ij}}$ 's are sometimes called the Principal Component Scores (PCS) and the $\boldsymbol{C}_{\boldsymbol{i}}$ 's are constants to be determined. The first principal component $\left(Z_{1}\right)$ is the linear combination with maximum variance in product processes [13].

\section{Discussion of results}

\subsection{Descriptive analysis}

The analyses of the initial Descriptive Statistics for the four Quality Characteristics of the product is given in Table 1 . The result obtained shows that the mean and standard deviation of three process variable are stable over time, but $\mathrm{X}_{3}$ is at optimum level in the production processes even though it range is within control limit as specified by [3].

Table 1: The Descriptive Analysis of the Process Variables of the Tablets

\begin{tabular}{lcccc}
\hline \multicolumn{5}{c}{ Simple Statistics } \\
\hline \multirow{2}{*}{ Mean } & $\mathrm{X}_{1}$ & $\mathrm{X}_{2}$ & $\mathrm{X}_{3}$ & $\mathrm{X}_{4}$ \\
StdDev & 7.55 & 94.12 & 337.7 & 97.43 \\
$\mathrm{~N}$ & 0.54 & 1.88 & 54.60 & 0.98 \\
Minimum & 6.45 & 90.18 & 260.0 & 95.26 \\
Maximum & 8.55 & 97.19 & 437.0 & 98.97 \\
\hline
\end{tabular}

\subsection{Analysis of results}

The control chart limits for Hotelling's $\mathrm{T}^{2}$ and MEWMA Charts are established here in Table 2, were the decision criteria stated

\begin{tabular}{|c|c|c|c|c|}
\hline Control Chart & Alpha-Value & P-Value & LCL & UCL \\
\hline Hotelling's $\mathrm{T}^{2}$ Chart & 0.01 & 0.27 & 0.0 & 13.836 \\
\hline MEWMA Chart & 0.01 & 0.27 & 0.0 & 13.836 \\
\hline
\end{tabular}
that the product process is stable and the MEWMA Chart smoothing parameter lambda $(\lambda)=0.2$ is considered.

Table 2: Control Chart Limits

Table 3 shows the existence of relationship between the several process variables of the product, which satisfies one of the assumptions of the distribution. However, the $\mathrm{X}_{4}$ is an essential physico-chemical property in producing the tablet. This is sufficient evidence that the correlation coefficient between $X_{1}$ and $X_{2}$ is $-0.2454, X_{1}$ and $X_{3}$ is 0.0234 and finally $X_{1}$ and $X_{4}$ is -0.0337 ,

\begin{tabular}{|c|c|c|c|c|}
\hline & & Correlation & Matrix & \\
\hline & $\mathrm{X}_{1}$ & $\mathrm{X}_{2}$ & $\mathrm{X}_{3}$ & $\mathrm{X}_{4}$ \\
\hline $\mathrm{X}_{1}$ & 1.0000 & -0.2454 & 0.0234 & -0.0337 \\
\hline $\mathrm{X}_{2}$ & -0.2454 & 1.0000 & 0.0083 & -0.0013 \\
\hline $\mathrm{X}_{3}$ & 0.0234 & 0.0083 & 1.0000 & -0.1064 \\
\hline $\mathrm{X}_{4}$ & -0.0337 & -0.0013 & -0.1064 & 1.0000 \\
\hline
\end{tabular}
which clearly confirms the visual impression obtained in the Matrix of scatter plots in Fig. 2.

Table 3: The Correlation Matrix Result

Table 4 gives the result of covariance between each and pair of the process variables and the $\mathrm{X}_{4}$ still retained its reputation towards

\begin{tabular}{|c|c|c|c|c|}
\hline \multicolumn{5}{|c|}{ Covariance Matrix } \\
\hline & $\mathrm{X}_{1}$ & $\mathrm{X}_{2}$ & $\mathrm{X}_{3}$ & $\mathrm{X}_{4}$ \\
\hline$X_{1}$ & 0.2955 & -0.2508 & 0.6957 & -0.0180 \\
\hline$X_{2}$ & -0.2508 & 3.5341 & 0.8512 & -0.0024 \\
\hline$X_{3}$ & 0.6957 & 0.8512 & 2980.6436 & -5.7059 \\
\hline$X_{4}$ & -0.0180 & -0.0024 & -5.7059 & 0.9639 \\
\hline
\end{tabular}
conformance of specification and standard among other process variables.

Table 4: The Covariance Matrix

\subsubsection{Numerical computation of PCA}

In Table 5, the eigen values satisfied the stated principles of the PCA, were the first eigen value $\geq$ second eigen value... $\geq$ fourth eigen value $\geq 0$. Also, the Proportion Percent and Cumulative Proportion Percent are accounted to explain the amount of variability among the process variables by each of the Principal Component (PC). The Scree plot in Fig. 3 suggest to retain the first PC which explain over $99 \%$ of the total variability among the initial four process variable of the official physico-chemical quality of chloroquine tablet BP250mg. However, the eigen vectors exhibited a strong support and play a vital role towards building the uncorrelated PCS to be retained for a better and reliable detection of the outliers or shift in mean and variability. 


\begin{tabular}{|c|c|c|c|c|}
\hline EigenValues & 2980.6549 & 3.5531 & 0.9534 & 0.2756 \\
\hline Proportion & 0.9984 & 0.0012 & 0.0003 & 0.0001 \\
\hline \multirow[t]{3}{*}{ Cumulative Proportion } & 0.9984 & 0.9996 & 0.9999 & 1.0000 \\
\hline & \multicolumn{4}{|c|}{ EigenVectors } \\
\hline & PC1 & PC2 & PC3 & PC4 \\
\hline $\mathrm{X}_{1}$ & 0.0002 & -0.0768 & -0.0245 & 0.9967 \\
\hline $\mathrm{X}_{2}$ & 0.0003 & 0.9970 & -0.0021 & 0.0768 \\
\hline $\mathrm{X}_{3}$ & 0.9991 & -0.0003 & 0.0019 & -0.0002 \\
\hline $\mathrm{X}_{4}$ & -0.0019 & 0.0002 & 0.9997 & 0.0246 \\
\hline
\end{tabular}

\subsection{Control charts and plot presentations}

\subsubsection{Test of Box/Normallity plots}

The box plots nomallity test shows that all the physico-chemical quality measurements in Fig. 1 are approximately normally distributed which satisfied the most important assumption of MSPC.

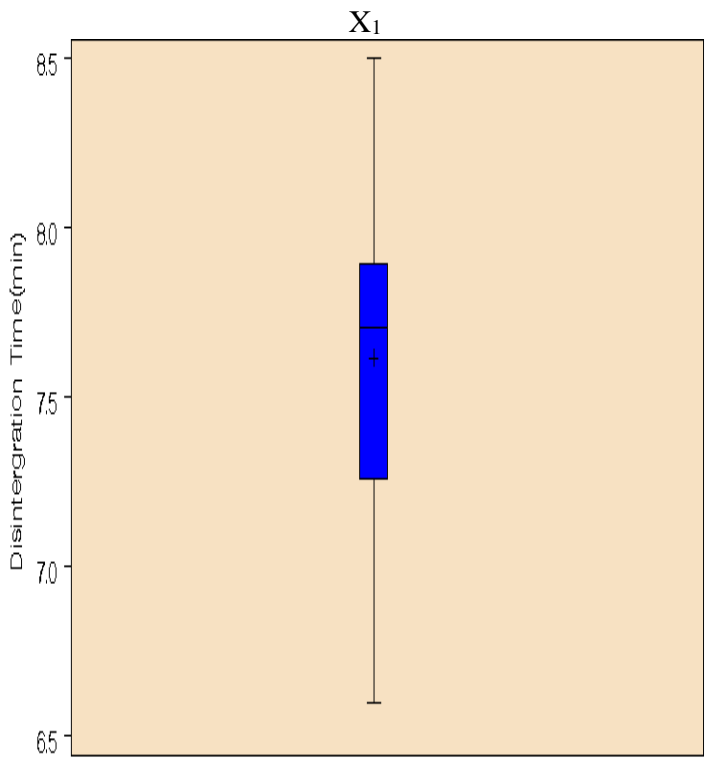

$\mathrm{X}_{2}$

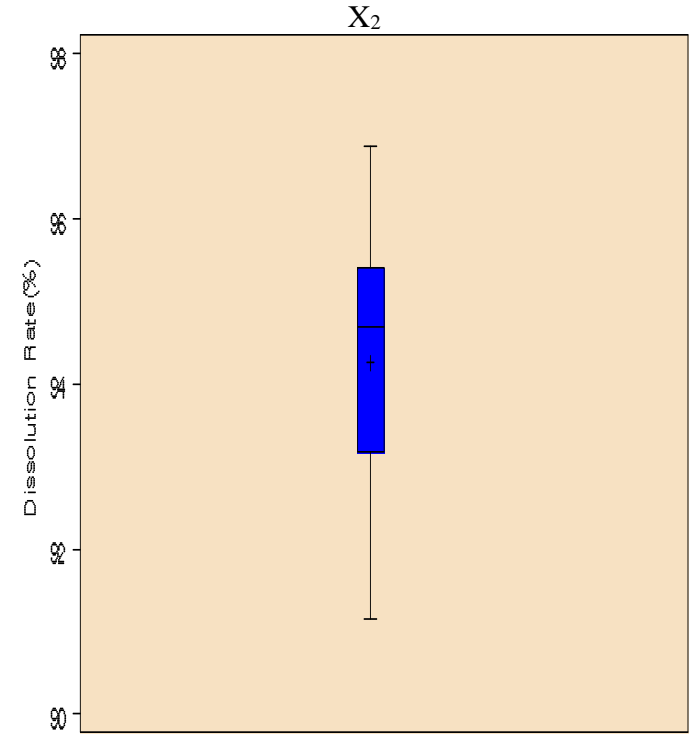

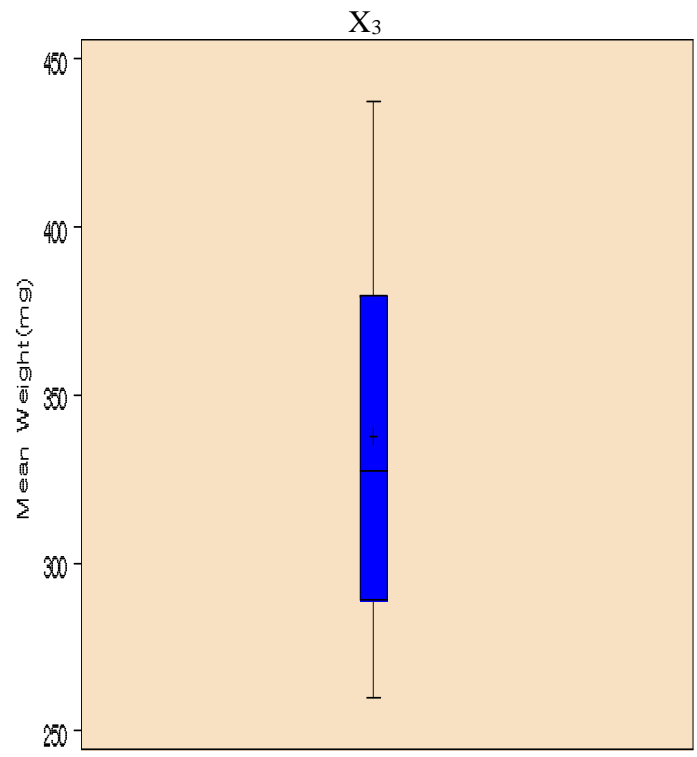

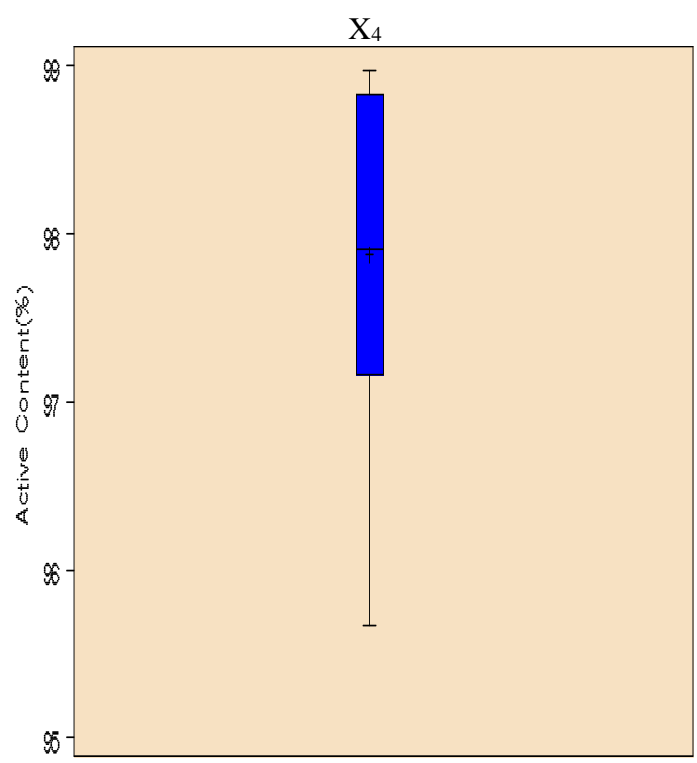

Fig. 1: Box Plot Test of Normality for the four Process Variablesof the Tablets

\subsubsection{Matrix of scatter plots}

Fig. 2 displayed a Matrix of scatter plots for the 40 observations on the four physico-chemical process variables. The plots comply with the results above in Table 3 which stated that some of the pairs of process variables are negatively correlated while others exhibit moderate relationship and the ellipses indicate $99 \%$ approximately control limits. 

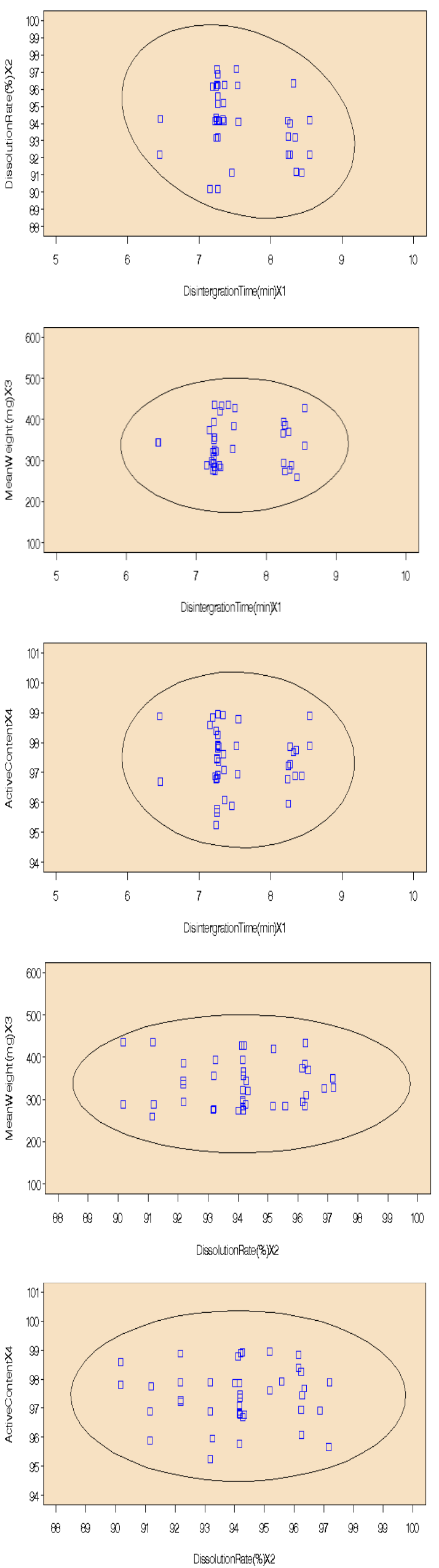

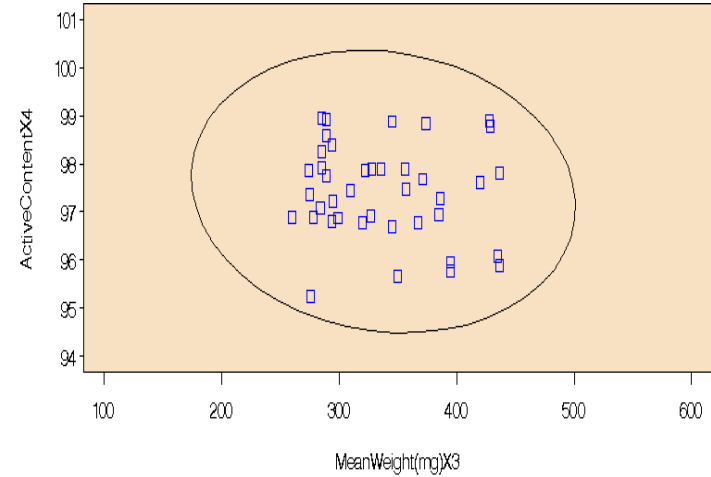

Fig. 2: Correlation Matrix of Scatter Plots for the Four Process Variables of the Tablets

\subsubsection{Hotelling's $T^{2}$-control chart}

This chart describes how the product process is fluctuating over a period of time and it complies with the result in Table 2 through the graphical presentation in Fig. 3. However, the process is in control but indicates need for adjustment in future production processes.

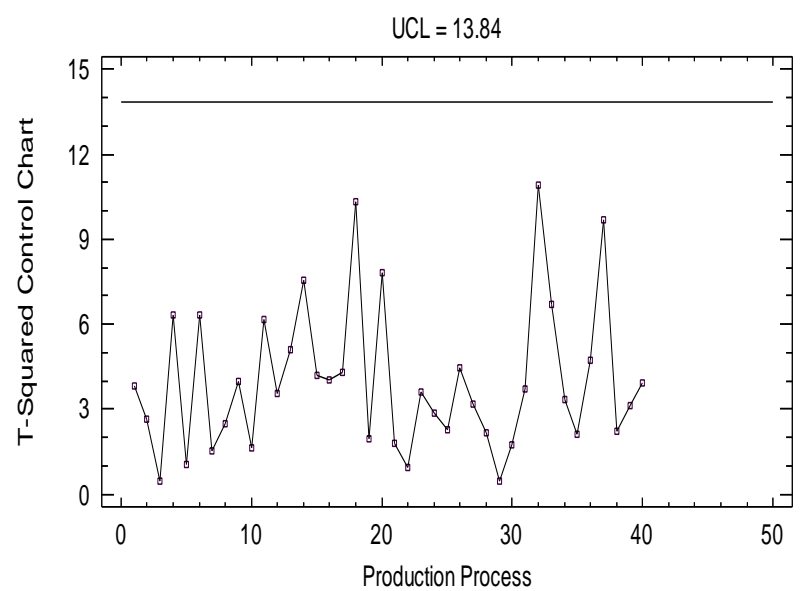

Fig. 3: Hotelling's $T^{2}$ Control Chart of the Process Variables

\subsubsection{MEWMA control chart}

The MEWMA Chart describes how the product process is fluctuating over a period of time with a smoothing parameter lambda $=$ 0.2 and it also confirm the result in Table 2 through the graphical presentation in Fig. 4. Therefore, this chart clearly shows that the product process variability are statistically stable and conform to specification, It also reveals the negligence of the traditional Hotelling's $\mathrm{T}^{2}$-Chart in detecting small and even moderate shift in the process means.

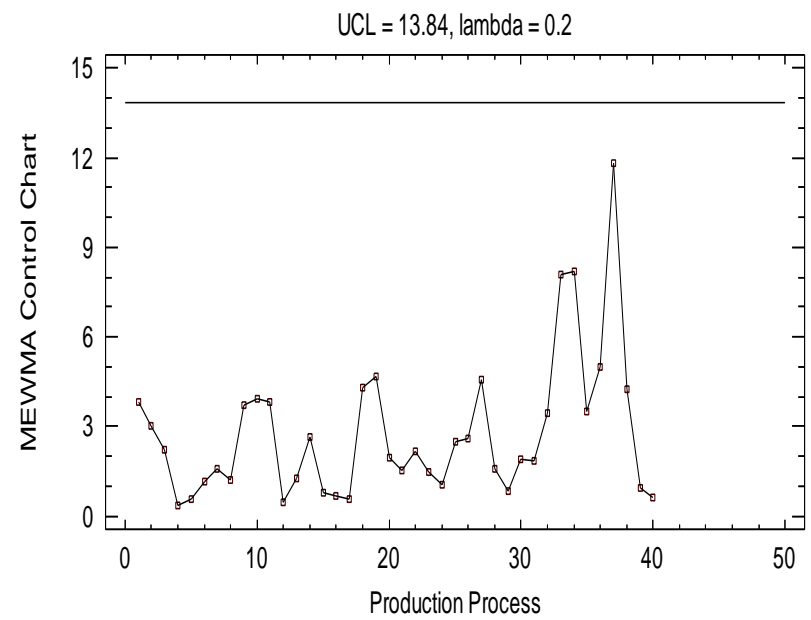

Fig. 4: MEWMA Control Chart of the Process Variables. 


\subsubsection{Scree plot}

This plot in Fig. 5 suggests retaining the first PC, which can explain over $99 \%$ of the total variability among the process variables of the product.

Scree Plot

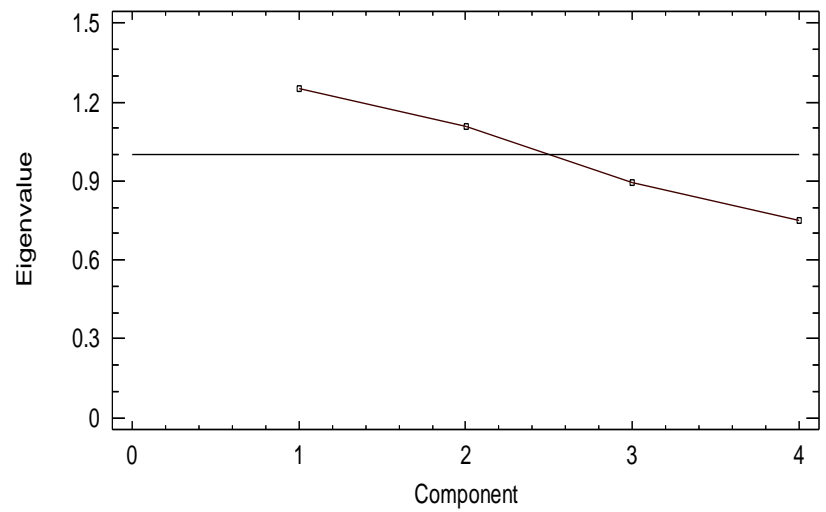

Fig. 5: Scree Plot of the Uncorrelated Principal Components of the Tablets.

\subsubsection{PCS's plot}

By default, it is difficult to detect the variable outliers using plot of one PC as suggested in Fig. 5. Therefore, we retain the first two uncorrelated PC and their plots as presented in Fig. 6 indicated that the product process variability is random. Hence, the official physico-chemical Qualities of Chloroquine Phosphate Tablet (BP250mg) is in control and conform to international standard as specified by [3].

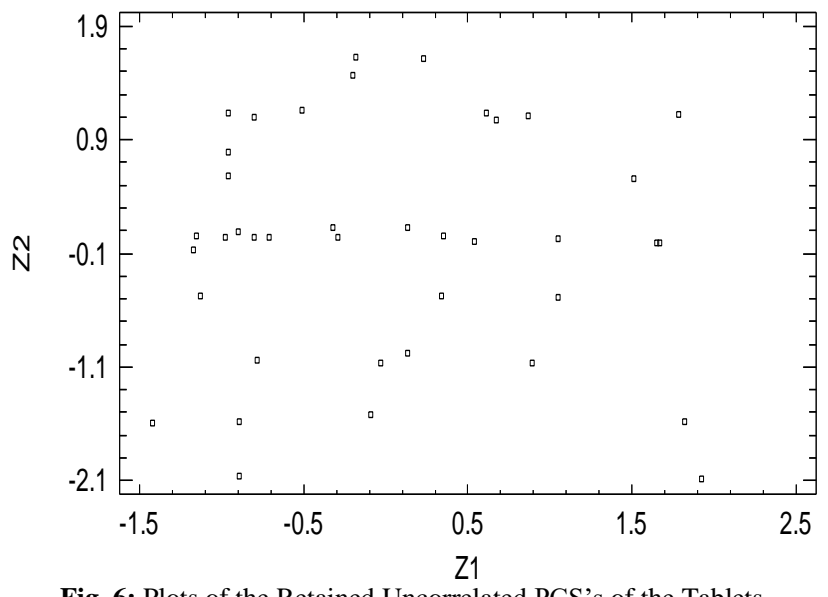

Fig. 6: Plots of the Retained Uncorrelated PCS's of the Tablets.

\section{Conclusion}

MSPC approach appeared to be an effective technique in assessing the quality of this product. This study examined the official physico-chemical quality of anti-malaria drug (Chloroquine Phosphate Tablet BP250mg) and provides sufficient evidence that the product quality characteristics are stable statistically and conform to international standard as specified by [3].

\section{Acknowledgement}

The corresponding author would like to use this medium to sincerely acknowledge the intellectual guidance, encouragement, kind assistants and support enjoyed by Prof. A.P. Nagwai, from Department of Mathematics and Statistics, Ewe University, Ghana, Prof. H. Musa and Dr. A. Yonni from Department of Pharmaceutics and Pharmaceutical Microbiology, Ahmadu Bello Univer- sity, Zaria whose ensured that this work is balanced and completed in good time. Also, he appreciation and acknowledge the prayers, moral effort and financial support received from his beloved one's in persons of Mallam Yusuf Umar, Hajiya Khadijah Adamu Umar, Alhaji Umar Abubakar and the entire family.

\section{References}

[1] Andres, C and Jorge, S. (2011). Multivariate Process Control by transition scheme in soft drink production process using 3-Way PLS Aproach. 11th International Congress on Engineering and Food, Procedia Food Science 1 (2011) 1181 - 1187, Elsevier. https://doi.org/10.1016/j.profoo.2011.09.176.

[2] Bakare, M. T., Garba, M. and Balat, L. (2006). Quality Control of Some Brands of Chloroquine Tablets Available in Nigeria. Nigerian Journal of Pharmaceutical Research, 5 (1).

[3] British Pharmacoepia. (2002). Vol I and II. The Majesty's Stationaries office; University Press Cambridge.

[4] Gasper, S., Rok, V., Peter, B. and Alojzij, S. (2013). Statistical Process Control as a Service. Forty Sixth CIRP Conference on Manufacturing Systems 2013. Procedia CIRP 7 (2013) 401 - 406. Elsevier.

[5] Justina, O. O., Ehijie, F. E. and Okhamafe, A. O. (2007). A Study of the Pharmaceutical Quality of Chloroquine and Paracetamo Products Sold in Major Nigerian Market. African Journal of Health Science, 14(3-4).

[6] Lowry, C. A., Woodall, W. H., Champ, C. W. and Rigdon, S. E. (1992). A Multivariate Exponentially Weighted Moving Average Control Chart. Technometrics, Vol.34, No.1, pp $47-$ 58.https://doi.org/10.2307/1269551.

[7] Mekki, H. (2015). On the Charting Procedures: Multivariate EWMA Chart and DD-Diagram. Open Journal of Statistics, 2015, 5, 373-381. https://doi.org/10.4236/ojs.2015.55039.

[8] Michal, R. (2012). Some Notes on Multivariate Statistical Process Control. Journal of Management and Production Engineering, 3(4), 80-86. DOI: 10.2478/v1070-012-036-7.

[9] Montgomery, D. C. (2005). Introduction to Statistical Quality Control. $5^{\text {th }}$ Ed, New York: John Wiley and Sons.

[10] Montgomery, D. C. (2009). Statistical Quality Control. 6 ${ }^{\text {th }} \mathrm{Ed}$, USA: John Wiley \& Sons, Inc.

[11] Musa, H., Sule, Y. Z. and Gwarzo, M. S. (2011). Assessment of Physico-Chemical Properties/Quality of Metronidazole Tablets. International Journal of Pharmacy and Pharmaceutical Sciences, 3 (3), 27-29.

[12] Musa, H., and Yahaya, A. (2008). Assessment of Physico-Chemical Properties/Quality of Chloroquine Phosphate Tablet. Department of Pharmaceutics and Pharmaceutical Microbiology, Ahmadu Bello University, Zaria. Unpublished.

[13] Richard A. J. and Dean W. W. (2007). Applied Multivariate Statistical Analysis. $6^{\text {th }}$ Ed, USA: Pearson Prentice Hall.

[14] Samali, A., Mohammed, M. I., Ibrahim, M. B. and Gamaniel, K. S. (2014). Quality Status of Brands of Chloroquine Tablet Dosage from Northern part of Nigeria. Journal of Chemical and Pharmaceutical Research, 6(11): 75-79.

[15] Usman A. (2012). Statistical Methods for Biometric and Medical Research. Revised Ed, Kaduna: Millennium Printing and Publishing Company Limited.

[16] Woodall, W. H. and Montgomery, D. C. (1999). Research Issues and Ideas in Statistical Process Control. Journal of Quality Technology 31: 376-380.

[17] World Health Organization (1999). Annual Report on Drug Quality Control Laboratories. WHO/AFRO/EDP/99.7.

[18] Yakasai, I. A., Musa, H. and Anuka, J. A. (2009). Effect of TamarindusIndica $\mathrm{L}$ on the Bioavailability of Chloroquine in Healthy Human Volunteers. Bulletin of SAN, 26(2005): 596-605. 